\title{
Selection of a representative dolerite waste sample for use in erosion assessments using remote sensing techniques
}

\author{
EJ Howard Landloch Pty Ltd, Australia \\ MD Bettison BHP, Australia
}

\begin{abstract}
Rehabilitation of the W39 Overburden Storage Area (OSA) is currently being planned by BHP. The W39 OSA is located at the Mt Whaleback iron ore mine site in the Pilbara region of Western Australia.

The proposed OSA batter design utilises Banded Iron Formation (BIF) waste to sheet the majority of the batter slopes except for a $20 \mathrm{~m}$ high section that is to be sheeted with durable, competent dolerite waste rock currently stockpiled on an adjacent OSA. The stockpile is 25 ha in size and contains dolerite with a range of particle sizes.

Key to the erosion stability of the rehabilitation design is the erosion resistance of the dolerite, which in turn is largely a function of the dolerite's particle size distribution. It is therefore critical that the materials selected for erosion testing from the 25 ha stockpile are representative of the material as a whole.

In order to select a representative waste sample, a combination of remote sensing techniques was employed. Ortho-rectified imagery was sourced from a drone survey. The drone image was then divided into smaller 1-ha cells, and digital photographic techniques were used to determine the particle size distribution and mean rock size for each of the cells. The information for each cell was then combined to produce a map of changing mean rock size over the entire stockpile. From that mapping, representative locations were selected for testing, and areas of finer particle size were identified for exclusion from future rehabilitation works.
\end{abstract}

This paper outlines the importance of selecting representative samples, details the methods used to select a representative dolerite waste sample, and provides results of the study.

Keywords: sampling, representativeness, drone imagery, remote sensing

\section{Introduction}

The W39 Overburden Storage Area (OSA) is located at the Mt Whaleback Iron Ore Mine in the Pilbara region of Western Australia. Rehabilitation of the W39 OSA is currently being planned, and rehabilitation will involve the formation of a number of concave and uniform-shaped lifts. The lifts will be sheeted predominantly with Banded Iron Formation (BIF) waste interspersed by wide, back-sloping benches designed to store runoff generated from rare storm events (0.1\% Annual Exceedance Probability). The BIF-sheeted batter design was previously modelled using both the Water Erosion Prediction Project (WEPP) erosion model and the SIBERIA landform evolution model. These models were calibrated using laboratory-based methods shown to produce accurate erosion predictions (Howard \& Roddy 2012; Howard 2018).

The rehabilitation plan included the use of a lift of durable, competent dolerite waste rock located amongst lifts otherwise sheeted with BIF (Figure 1). The erosion potential of the dolerite was unknown, necessitating an assessment of erosion of a batter profile that included the dolerite waste. The dolerite to be sourced was located in a paddock-dumped stockpile on the top of a neighbouring OSA (Figure 2). The size of the dolerite stockpile was 25 ha. During a field inspection of the dolerite, it was determined that much of the dolerite was coarse-grained, though there was an appreciable proportion of fines. The field observations also indicated that there was an observable variation in particle size distribution across the dolerite 
stockpile. Therefore, in order for the erosion potential of the dolerite waste to be assessed and ultimately used within rehabilitation of the OSA, it was important to first consider the variability of the dolerite material so that representative samples could be selected for testing of erosion potential. In particular, the variability in particle size distribution is important for erosion studies. It was also important to identify areas of the stockpile that were not suitable for use in rehabilitation due to a particle size distribution that was too fine-grained.

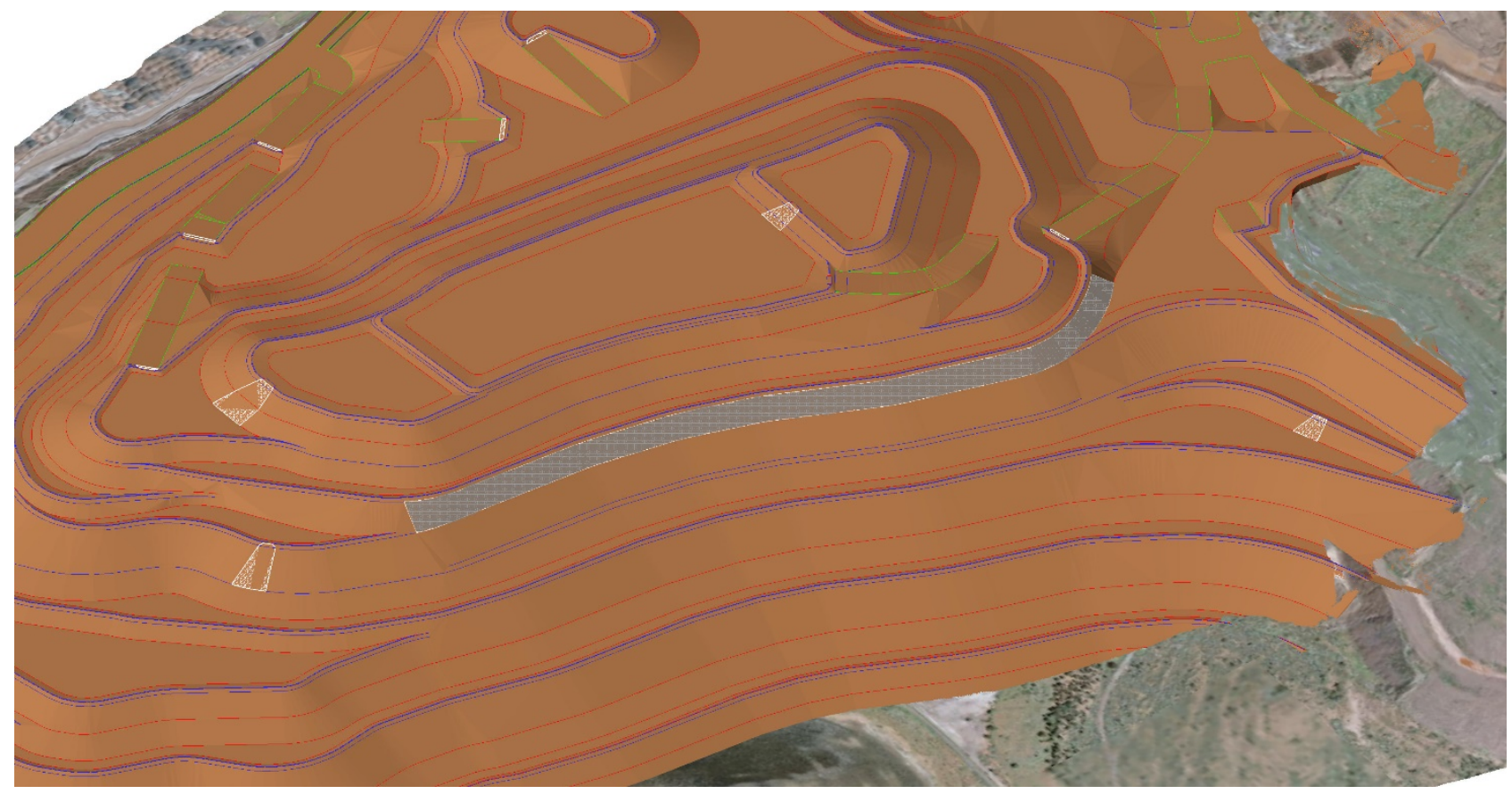

Figure 1 Section of dolerite waste (shaded grey) located within lifts that are sheeted with BIF waste (shaded brown)

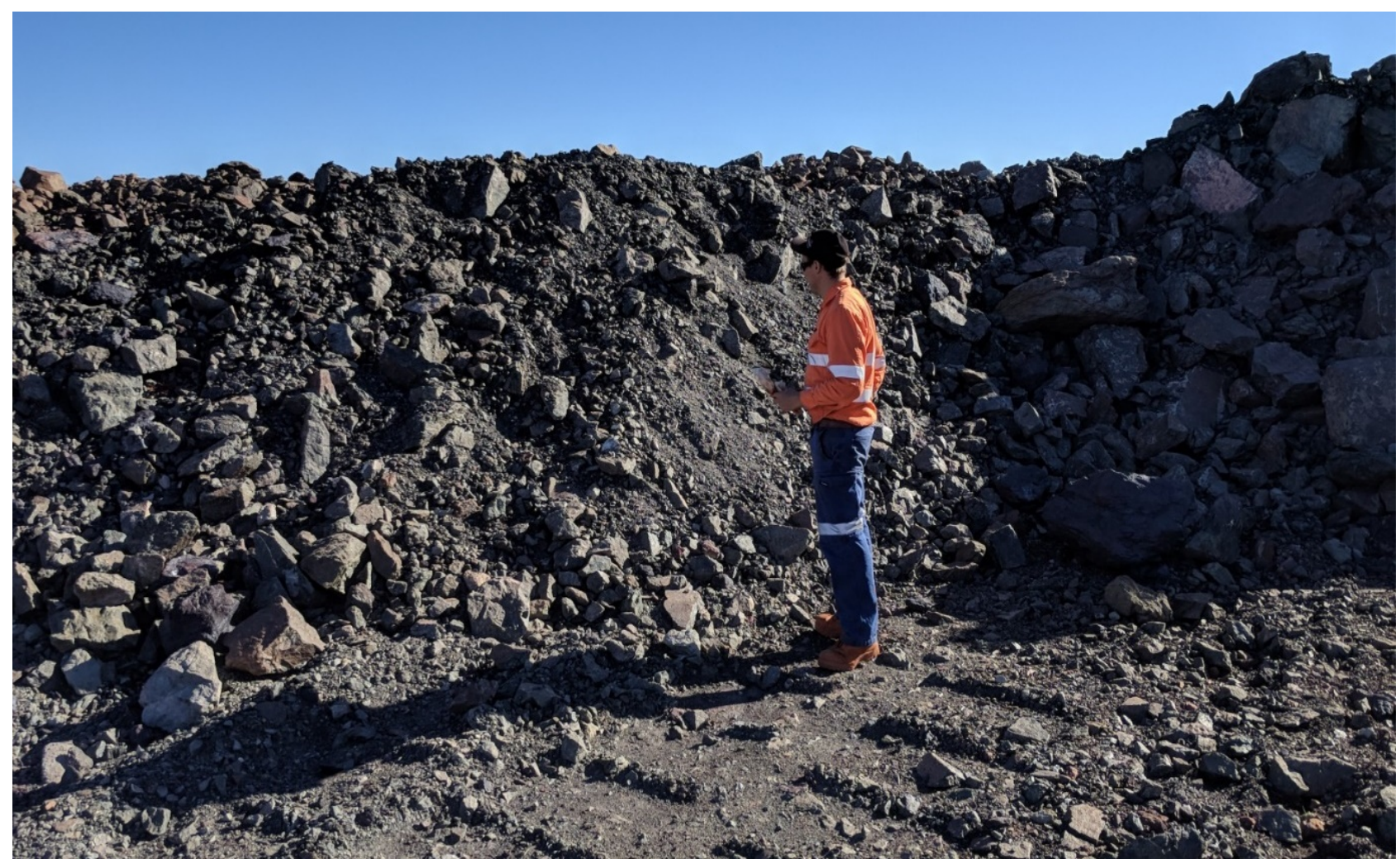

Figure 2 Stockpiled dolerite material 
In order to address the issue of material property variability and to select a representative dolerite sample, a combination of remote sensing techniques was employed. These techniques included the capture of drone imagery, segmentation of this image into smaller tiles, processing of these tiles to generate particle size distribution (PSD) curves and assessment of the variability of these PSDs.

\section{Importance of selecting a representative waste sample}

A representative sample is one that captures the characteristics of interest of the material being sampled. The International (ASTM) Standard D 6044-96 defines a representative sample as 'a sample collected in such a manner that it reflects one or more characteristics of interest of a population from which it was collected' (ASTM International 2009). In the context of the assessment of the dolerite stockpile, a representative sample is one that reflects the erosion characteristics of the stockpiled dolerite.

A strong determinant of erosion potential of rocky wastes is their rock size distribution and density. Assuming that the density of the dolerite is relatively consistent, it was concluded that rock size (as defined by PSDs) is an appropriate surrogate for considering representativeness of the dolerite based on its erosion potential.

Selection of representative samples is important. In the case of assessing erosion, selection of a dolerite sample that is coarser-grained than the dolerite typically stockpiled could result in an overestimate in erosion protection that could be provided by the dolerite. This could result in accelerated erosion and failure to meet agreed closure objectives. Depending on the degree of failure, the costs to remediate may be high and the remediation may be difficult or essentially impossible to implement. Selection of a dolerite sample that is finer grained than the majority of the dolerite could lead to the creation of rehabilitation slopes that are overly conservative, use a larger footprint and require more material to construct (impacting haulage costs).

\section{$3 \quad$ Workflow}

Dolerite was available for rehabilitation from a paddock-dumped stockpile on a neighbouring OSA. The paddock-dumped material was sitting in mounds $2-3 \mathrm{~m}$ high (Figure 3 ). An example of the variable PSDs observed across the stockpile is shown in Figure 4.

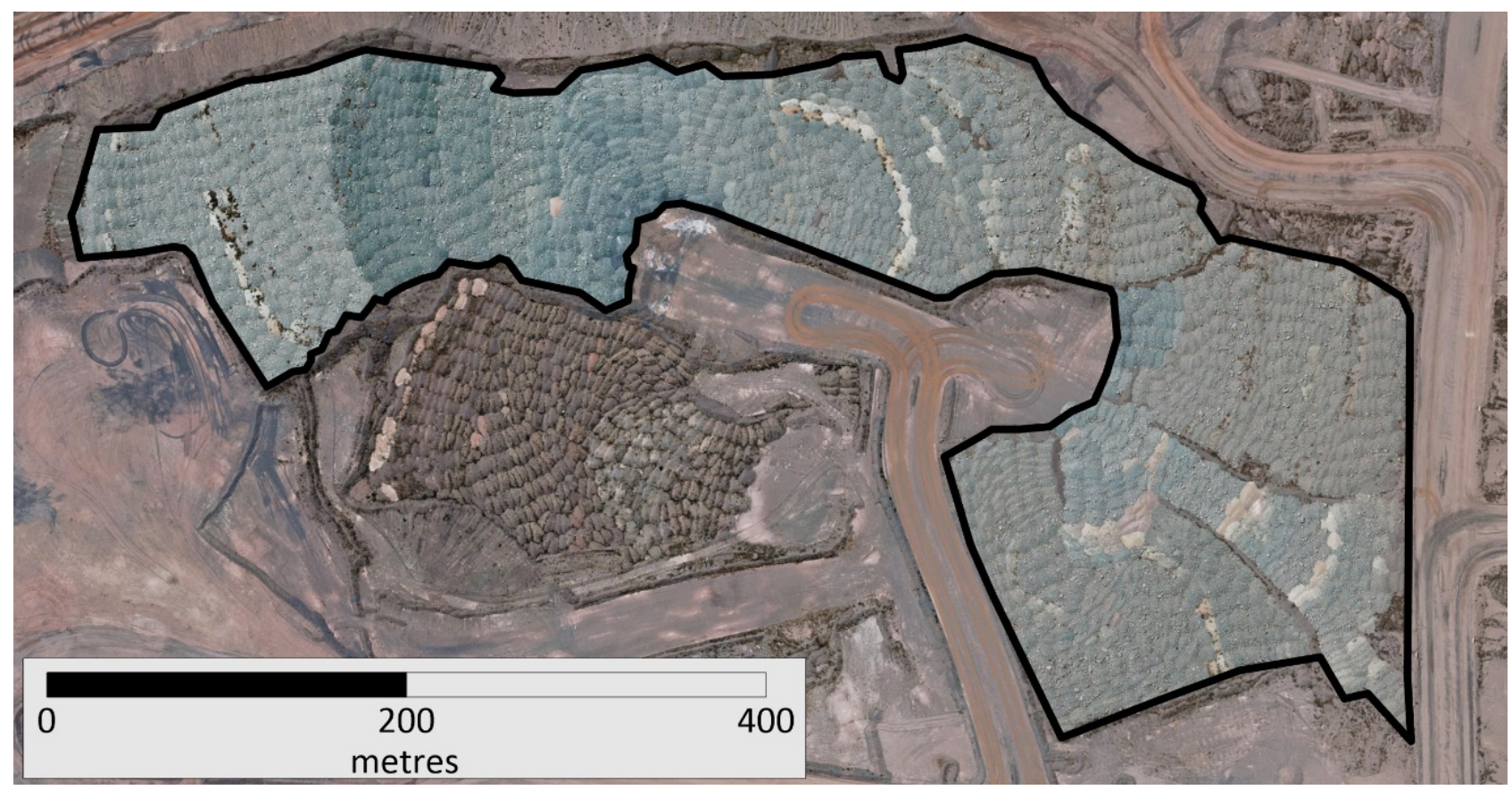

Figure 3 Paddock-dumped stockpile of dolerite to be used in rehabilitation of the W39 OSA (bounded by black polygon) 


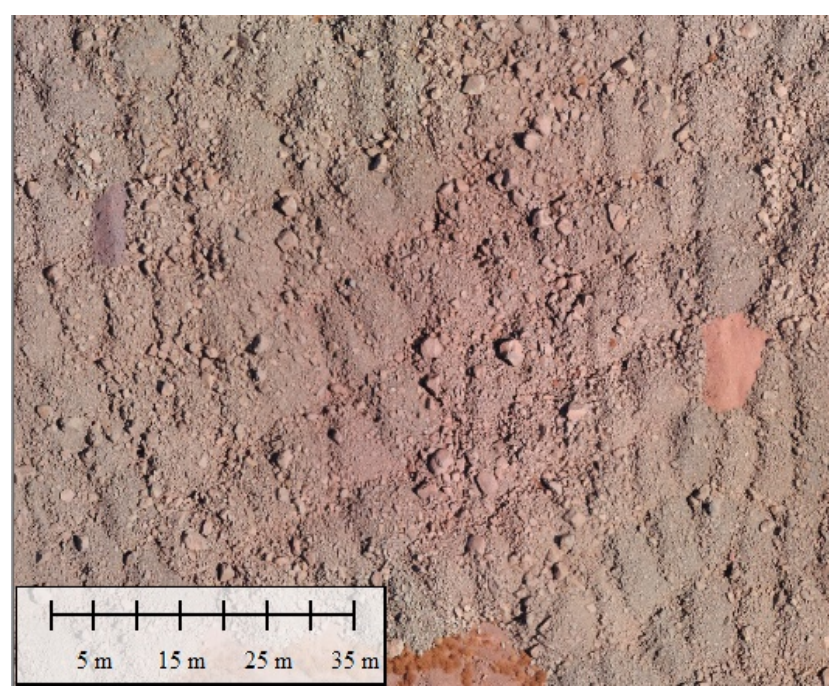

(a)

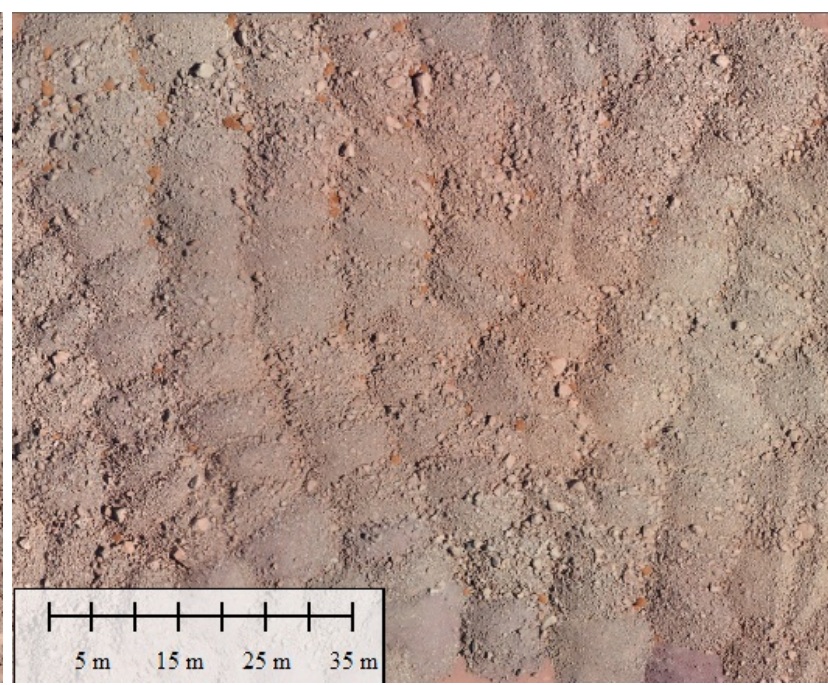

(b)

Figure 4 (a) Zones of coarser-grained material; (b) Finer-grained material within the dolerite stockpile

The workflow to assess variability of PSD within the stockpiled materials and to determine areas for selection of representative samples is given in Figure 5. Each step is described in detail below.

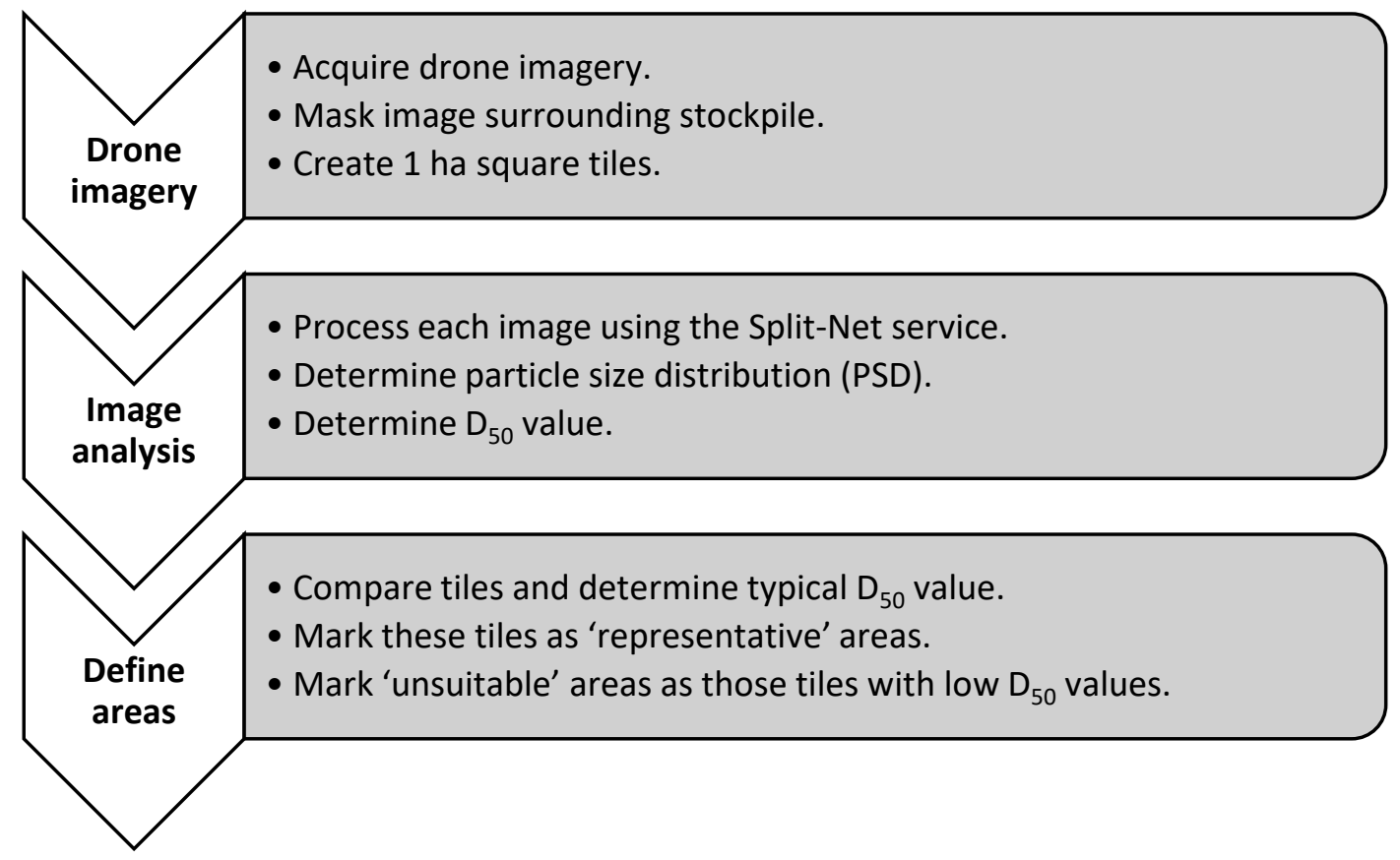

Figure 5 Workflow for defining representative and unsuitable areas

\subsection{Process drone imagery}

\subsubsection{Acquire drone imagery}

A drone flight was completed on 3 January 2018, with data used to create both a mosaic ortho-rectified aerial image and a digital surface model. The drone used was a fixed wing Sensefly eBee RTK fitted with an S.O.D.A photogrammetry camera, and it was flown at an altitude of $80 \mathrm{~m}$. The pixel width of the image was $20 \mathrm{~mm}$. Given this, it is unlikely that rock particles less than $100 \mathrm{~mm}$ would be differentiable in the image. Specifications of the camera and flight are given in Table 1 . The aerial image created is reproduced in Figure 6. 
Table 1 Camera specifications used to capture the drone image

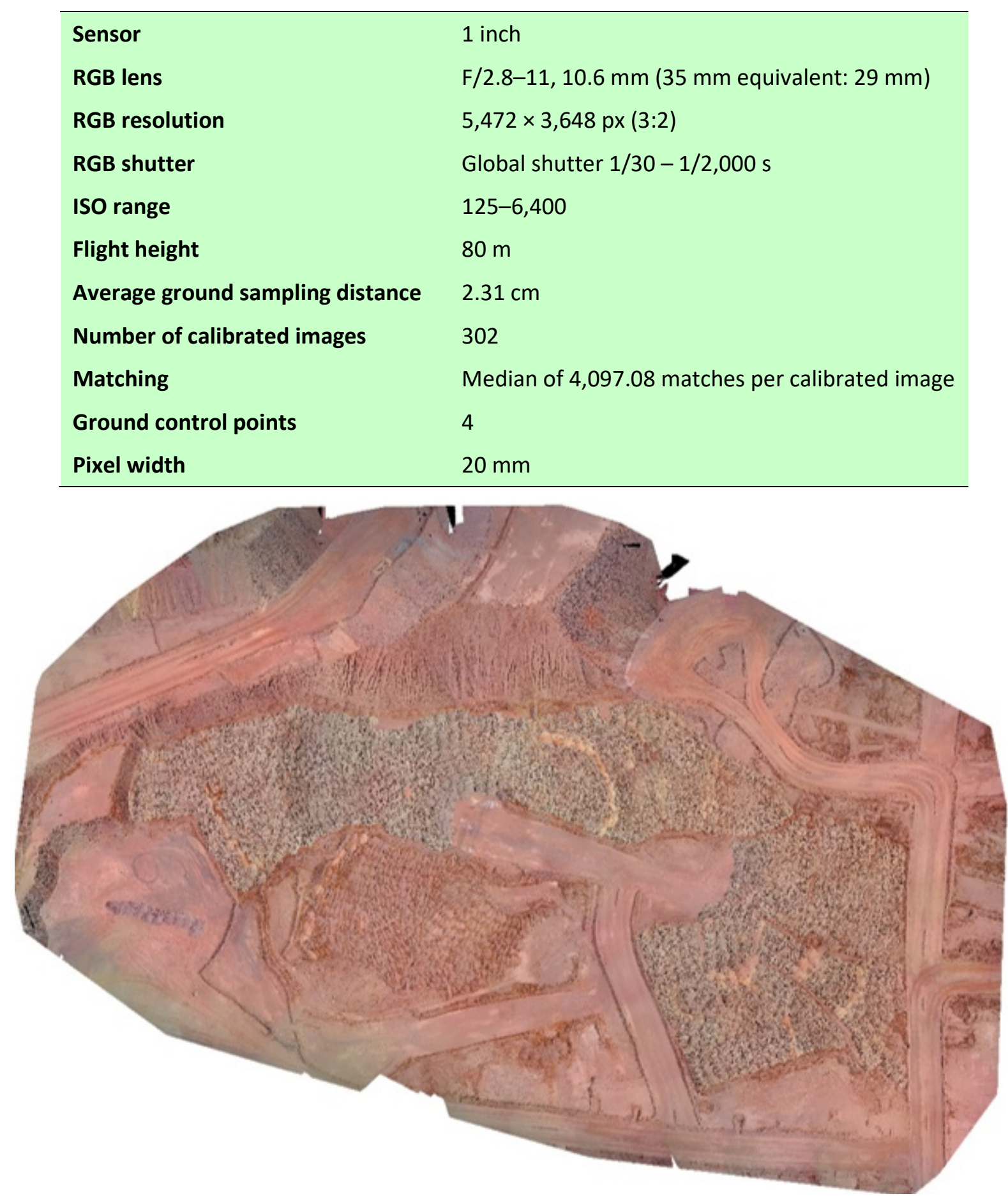

Figure 6 Aerial image produced from the drone flight

\subsubsection{Image processing}

The boundary of the dolerite stockpile was defined from the drone image by visually digitising the edges of the stockpile. The stockpile area then was split into individual square tiles that were each 1 ha in size (Figure 7). The image area outside of the dolerite stockpile boundary was cropped out of the image (Figure 8) in preparation for processing the images for PSD. A total of 22 square tiles were created. Although each tile was 1 ha in size, the extent to which an image included dolerite stockpile varied between tiles. For some tiles covering the centre of the stockpile, the image data filled the entire tile; for tiles covering the edges of the stockpile, the image data only partially filled the tile. 


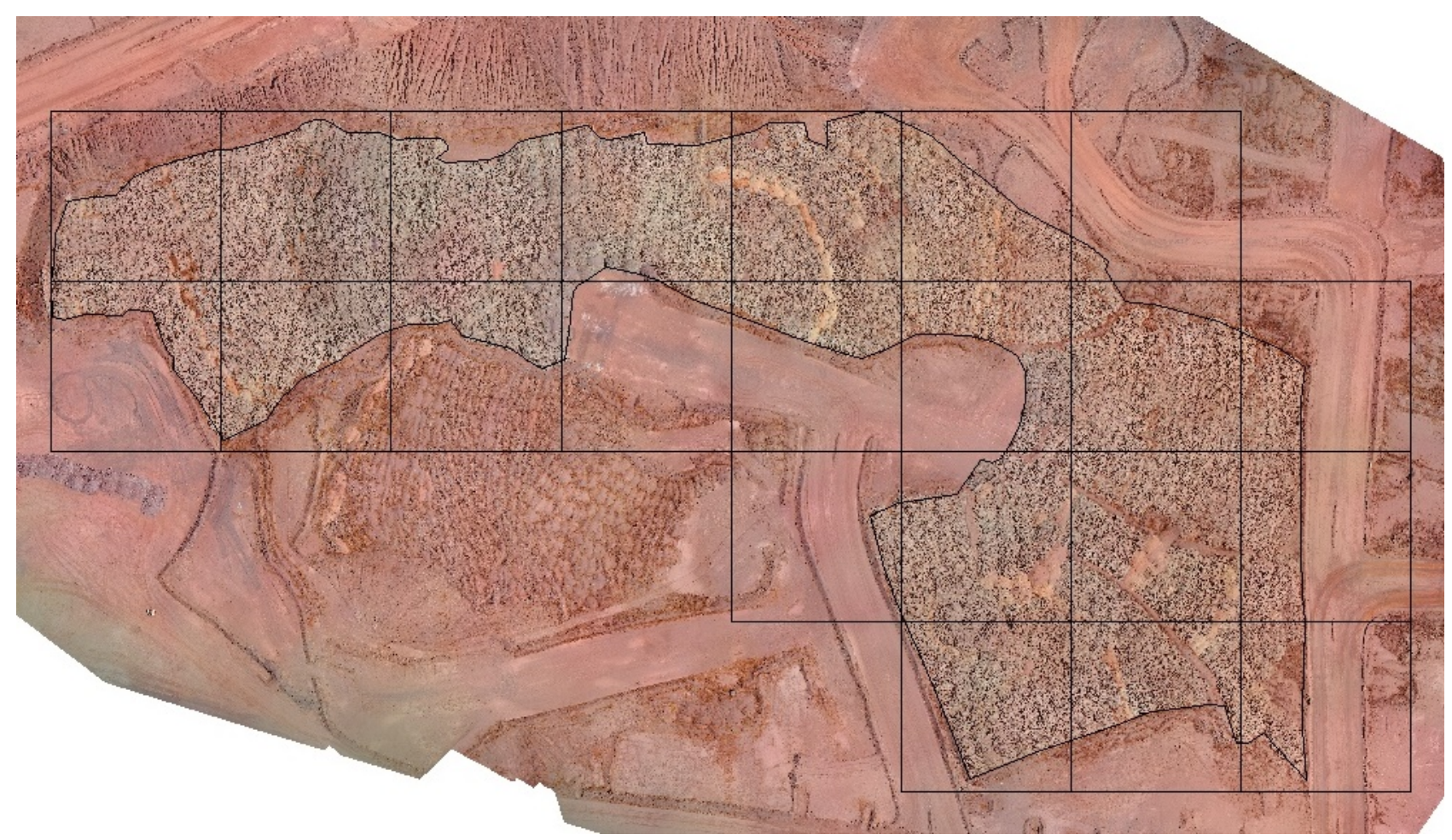

Figure 7 Square tiles each 1 ha in size covering the dolerite stockpile area
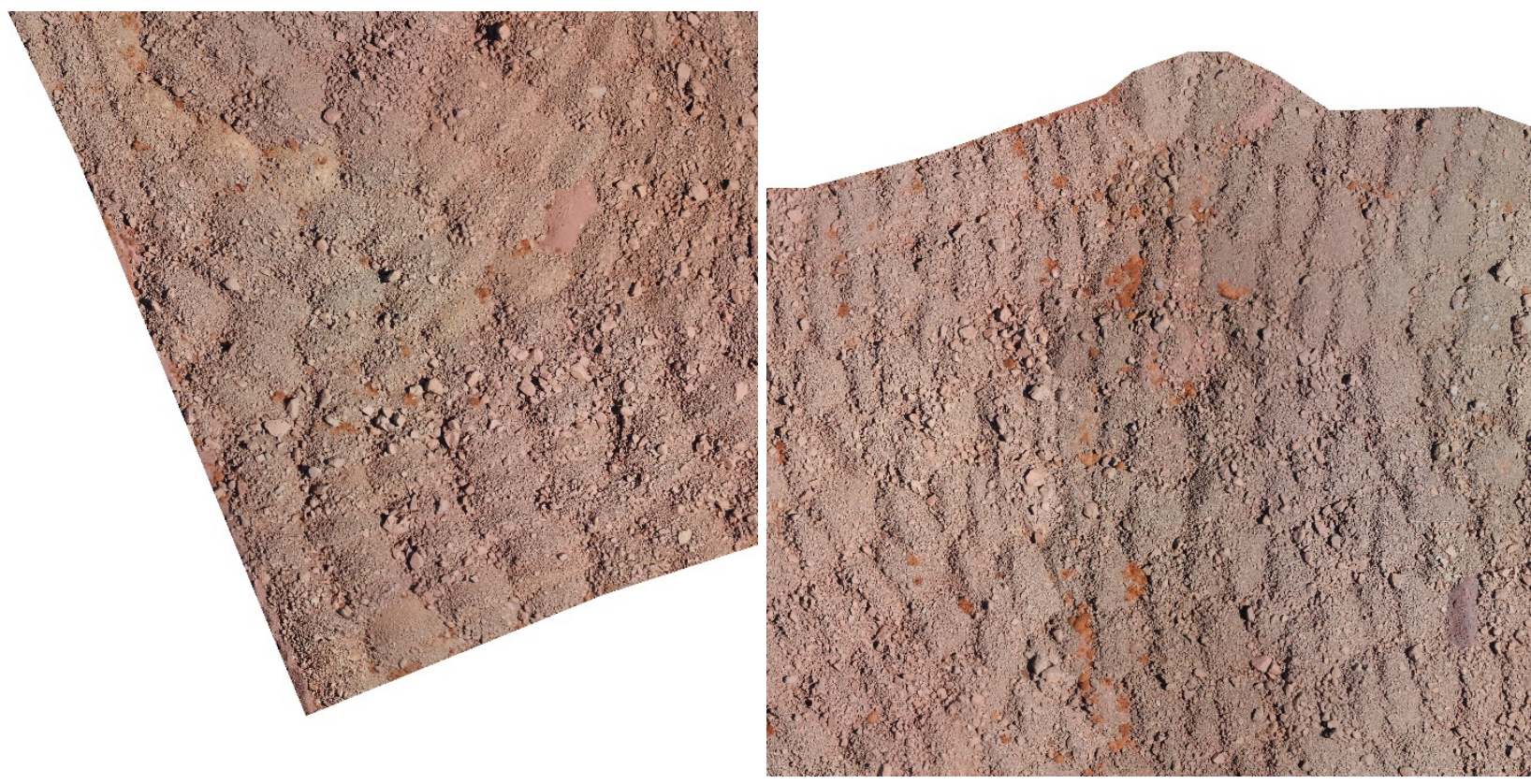

Figure 8 Example of individual tiles with image outside of stockpile cropped in preparation for image processing

\subsection{Digitally analyse drone imagery}

\subsubsection{Split-net service}

Each tile was processed for PSD using the Split-Net service (Split Engineering 2019). Scaling was achieved as each tile was an ortho-rectified image of a known size (1 ha). The Split-Net service processes a scaled image and produces a PSD curve of the visible rocky fragments within the image. Importantly, this PSD curve will be different to the PSD that is derived from the sieving of a bulk sample. There is also some inherent 
inaccuracies in the method given it is a digital technique. However, for the purposes of considering how materials vary within an area, it is suitable as the assessment is based on relative differences in PSD rather than absolute differences.

\subsubsection{Split-net outputs}

A PSD curve was generated for each 1-ha tile. The results are shown in Figure 9 as grey lines. Minimum and maximum data are shown by the red dashed lines, and the average data are shown by the black dotted line. The data are also tabulated in Table 2. The same method could be used on smaller tiles if a more detailed assessment is required. For the purposes of this study, 1-ha grids were considered appropriate.

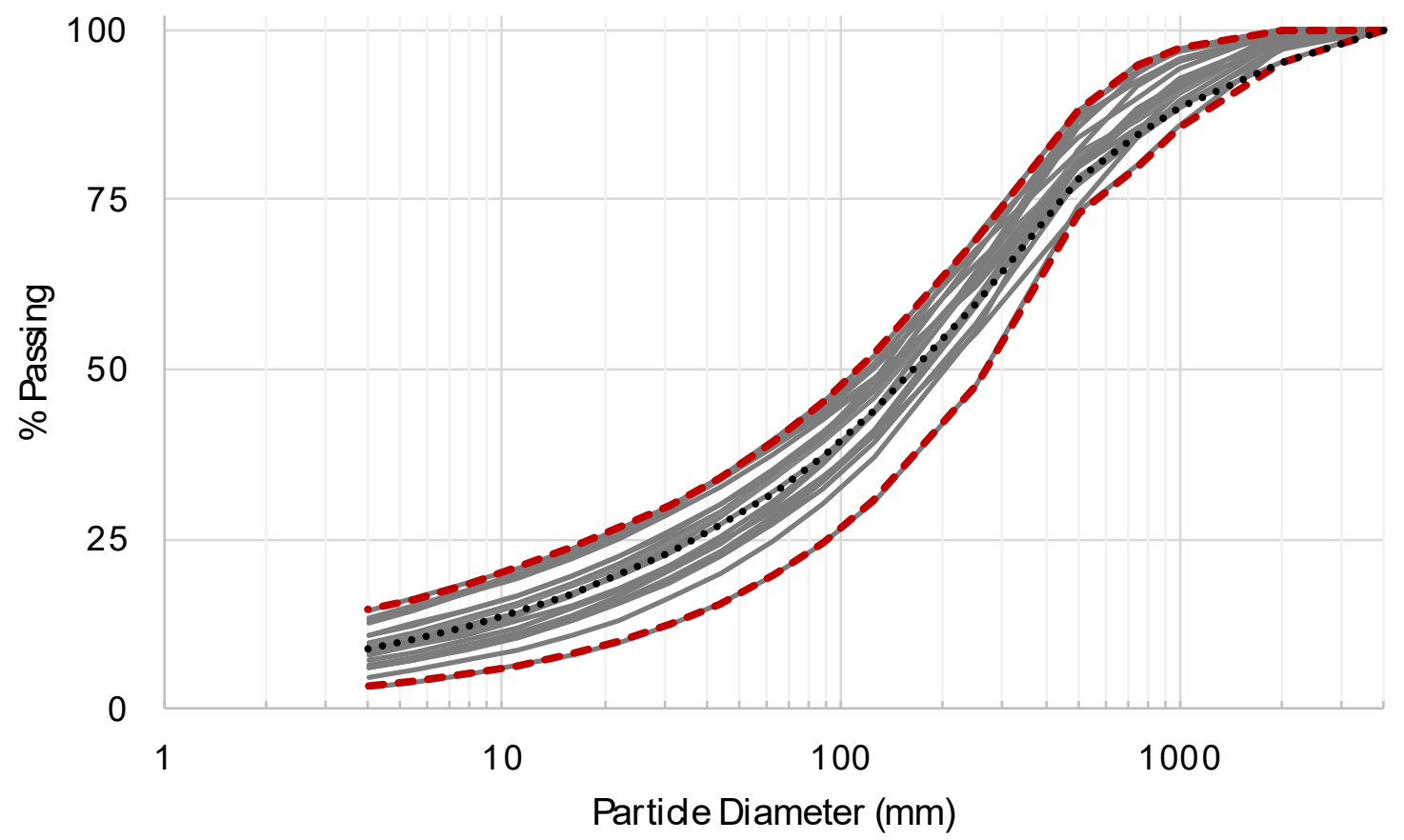

Figure 9 Particle size distribution curves for each of the 22 tiles (grey lines), the finest and coarsest curves (red dashed lines), and 'average' curve (black dotted line)

The Split-Net service reports the 'fines cutoff' value for each image, which is the rock size to which the SplitNet software can clearly delineate particles from the image. The fines cutoff value is dependent on the quality of the image. The PSD curve below the fines cutoff values are estimated using a Schuhmann or Rosin-Rammler distribution. This does not mean the estimated portions of the PSD curves are not useful because the Schuhmann or Rosin-Rammler distributions are commonly used to empirically describe similar curves. But it does provide a useful indicator of the limits to which the captured photos can be readily applied.

For the images tested, $70 \%$ of the images had cutoff fines values smaller than or within $10 \%$ of the $D_{50}$. This indicates the quality of the image was reasonable for the specific assessment, though use of higher quality imagery would be needed to delineate particles much smaller than rocks (e.g. gravels). This could be achieved by flying the drone at lower altitudes. The $D_{50}$ value was used to consider the relative differences between dolerite materials within each tile. The $D_{50}$ values ranged from $113-270 \mathrm{~mm}$, and the average $D_{50}$ was $163 \mathrm{~mm}$. Of the tiles, $55 \%$ had $D_{50}$ values of $113-150 \mathrm{~mm}, 32 \%$ had $D_{50}$ values of $150-190 \mathrm{~mm}, 9 \%$ had $D_{50}$ values of $190-230 \mathrm{~mm}$, and $4 \%$ had $D_{50}$ values of $230-270 \mathrm{~mm}$. The distribution of the different sized materials is shown in Figure 10. The materials with $D_{50}$ values of $113-190 \mathrm{~mm}$ (the two finer-grained groups of tiles identified) are evenly distributed across the east and west of the stockpile, whereas the zone to the west of the centre of the stockpile was identified as a zone that had coarser rock compared to the rest of the stockpile (Figure 10). 
Table 2 Particle size distribution data for the finest and coarsest tiles, and the average of all 22 curves

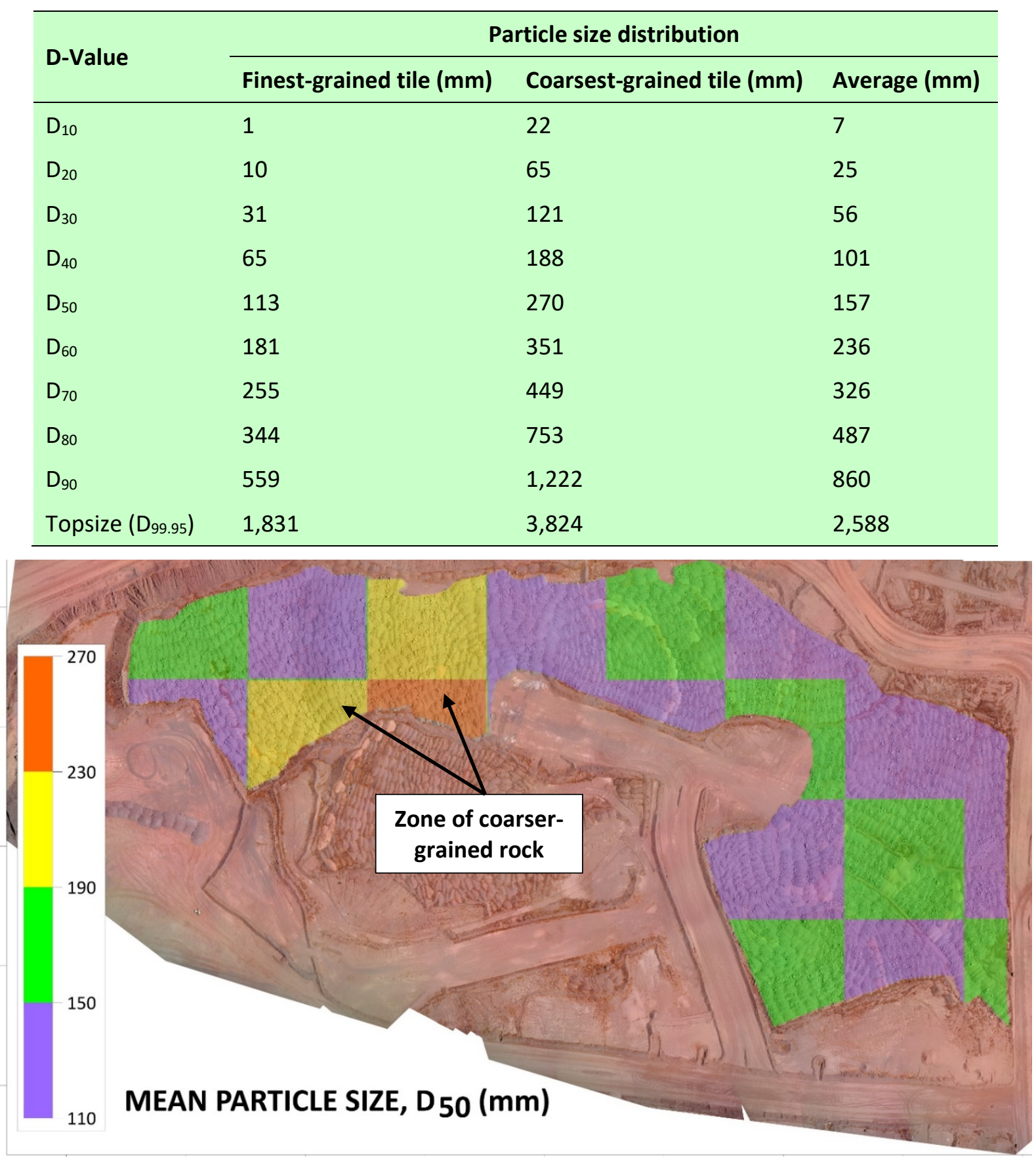

Figure 10 Distribution of tiles with differing $D_{50}$ values

\subsection{Define representative and unsuitable areas}

Rehabilitation of the W39 OSA will require use of the majority of the dolerite stockpile. Therefore, the data are best used to define a representative sample by selecting areas that have a $D_{50}$ that represents the majority of the materials. In this case, selection of materials within the green and purple shaded areas (Figure 10) would be appropriate. This means that, in this instance, the majority of the dolerite stockpile would be suitable for sampling of a representative sample. The areas shaded yellow and orange (Figure 10) were avoided as areas that are not representative of the stockpiled materials. Given the intent of the assessment was to identify materials for erosion testing, sampling and testing of the coarser materials would result in an overestimate in erosion protection that could be provided by the dolerite. 


\section{$4 \quad$ Possible changes to the workflow}

The workflow was developed to meet the specific needs of the assessment of the dolerite. Changes could be made to the workflow to apply the assessment in different situations or to improve accuracy.

For surfaces that are less rocky, higher resolution imagery would be desirable so that smaller-sized fragments could be delineated. The authors suggest that delineating particle much smaller than $100 \mathrm{~mm}$ with the available imagery would not be advised. The use of tiles that are smaller than 1 ha would increase the density of the data and allow more localised estimations of PSD to be made. This may be critical where only a small portion of the stockpile is to be used. It is suggested that the grid size should at least match the area of the stockpiles that is planned to be used. Increasing the density of the grid has a cost implication. Reducing the grid size from $100 \times 100 \mathrm{~m}(1 \mathrm{ha})$ to $50 \times 50 \mathrm{~m}$ would quadruple the number of images that need processing. It would also be possible to complete a staged assessment whereby larger tiles are assessed initially to broadly define zones with different PSD values. A subset of these areas could then be selected and re-tiled to produce higher density PSD data to more accurately define PSD values.

If knowing the absolute PSD values or the PSD of the bulk material is critical, the assessment should be coupled with ground-truthing data that would allow for calibration of the Split-Net results to measured data.

The assessment of PSD variability relied solely on the $D_{50}$ value in this instance. Different assessments could be performed using other parameters derived from the PSD curve. For example, the proportion of fines could be used as a measure of rockiness or rock cover. Assessment of the ratios of different D-values could be used to determine how well graded the rocky material is.

\section{Conclusion}

Selection of representative samples is an important part of sampling and testing. This paper provides a workflow used to determine the PSD variability of stockpiled dolerite to be tested for erosion potential as part of rehabilitation planning. The means by which the PSD data were used to define represented samples is also detailed.

There is a need to consider material variability and sample representativeness as part of all sampling and testing programs. This example workflow could be used prior to sampling of materials to ensure appropriate materials are selected and unsuitable materials avoided.

\section{References}

ASTM International 2009, Standard Guide for Representative Sampling for Management of Waste and Contaminated Media (D6044-96), West Conshohocken, Pennsylvania.

Howard, EJ 2018, 'Integrating erosion prediction into landform designs for rehabilitation and closure planning', Proceedings of the 2nd International Congress on Planning for Closure of Mining Operations, Gecamin, Santiago.

Howard, EJ \& Roddy BP, 2012, 'Evaluation of the water erosion prediction project model: validation data from sites in Western Australia', in AB Fourie \& M Tibbett (eds), Proceedings of the Seventh International Conference on Mine Closure, Australian Centre for Geomechanics, Perth, pp. 81-92.

Split Engineering 2019, Split-Net Instruction Manual, Tucson, viewed 3 April 2019, https://www.spliteng.com/downloads/SplitNet\%20Manual.pdf 
